ISSN: 2162-3104 Print/ ISSN: 2166-3750 Online

Volume 6, Issue 1 (2016), pp. 93-106

(C) Journal of International Students

http://jistudents.org/

\title{
Perceived Support as a Predictor of Acculturative Stress Among International Students in the United States
}

\author{
Jieru Bai \\ University of Nebraska at Omaha (USA)
}

\begin{abstract}
A quantitative study was conducted to measure the acculturative stress of international students and investigate the predictors of acculturative stress. A total of 186 students participated in the survey. Results showed that $22.4 \%$ of the students in this study exceeded the normal stress level and might need counseling or psychological intervention. International students from the Middle East had a significantly higher level of acculturative stress than students from other areas. Perceived support from the university was identified as a significant negative predictor of acculturative stress. The results have important implications for educators and helping professions in higher education settings that serve international students.
\end{abstract}

Keywords: acculturative stress, international students, support

According to the Institute of International Education, the number of international students enrolled in U.S. higher education institutions totaled 819,644 in 2012-2013 (IIE, 2014). The number has been increasing steadily since 2006. Currently, the United States has hosted more than half of the world's total number of international students and has become the primary destination for international students. In this study, international students are defined as foreign students enrolled in U.S. higher education institutions with F-1 (self-support students) or J-1 (exchange students) visa status.

Studying in a foreign country can impose numerous challenges on international students, including linguistic, accommodation, dietary, academic, financial, interpersonal, and intrapersonal problems (Mori, 2000; Pan, Yue, \& Chan, 2010). International students also report a variety of concerns related to social interaction, social connectedness, social support, 
homesickness, and other difficulties (Liu, 2009). It is estimated that $15 \%$ to $25 \%$ of all international students are at risk of experiencing psychological and psychiatric problems (Leong \& Chou, 2002).

All these concerns are part of the consequences of acculturation, a phenomenon where "individuals having different cultures come into continuous first-hand contact, with subsequent changes in the original culture patterns of either or both groups” (Redfield, Linton, \& Herskovits, 1936, p.149). When acculturation experiences cause problems for individuals, acculturative stress occurs (Berry, 2003). Acculturative stress is a negative side effect of acculturation. It can produce a reduction of individuals' physical, psychological, and social health (Berry, Kim, Minde, \& Mok, 1987).

Previous studies have reported much higher stress levels of international students than local students and many predictors of acculturative stress have been identified, such as English language proficiency, age of arrival, length of stay, educational level, socio-economic status (SES), marital status, ethnic identity, involuntary vs. voluntary immigration status (Constantine, Okazaki, \& Utsey, 2004; Kuo \& Roysircar, 2004). However, previous studies mainly focused on demographic and cultural elements, while school life itself was neglected. For international students, school life is the dominant part of their acculturation process. Academic stress could add a unique dimension to the acculturative stress of international students.

The purpose of this study was to measure levels of acculturative stress among international students in the United States and investigate the predictors of acculturative stress. In addition to the predictors mentioned in previous studies, school-related elements were included, such as academic achievement and perceived support from school. The researcher also compared the stress levels of students from different places of origin. The study has significant implications for educators and service providers for international students. The results can help professionals better understand international students' concerns and help them adapt to the life in the United States.

\section{LITERATURE REVIEW}

According to Berry and Kim (1987), there are five different acculturating groups, including immigrants, refugees, native peoples, ethnic groups, and sojourners. Previous studies do not pay equal research attention to different acculturating groups. Immigrants and refugees have received a lot of research attention, while student sojourners and other acculturating groups are less frequently studied. However, many studies have found that student sojourners have a higher level of acculturative stress compared to other 
acculturating groups (Berry et al., 1987; Kuo \& Roysircar, 2004; Liu, 2009). The following aspects make international students especially vulnerable to acculturative stress, including insufficient English proficiency, academic burden, lack of social support, and barriers to seeking professional help.

\section{Insufficient English Proficiency}

Many studies have reported that international students have insufficient English proficiency (e.g., Constantine et al., 2004; Kuo \& Roysircar, 2004; Mori, 2000). Although all international students who intend to apply for schools in the United States are required to take standard English tests from Educational Testing Services (ETS), the accuracy of standard tests are questioned. Particularly, people doubt how standard tests can examine students' fluency in spoken English. For example, Hwang and Ting (2008) found that Asian students had high test scores but still encountered great language barriers in daily communication.

Language ability is found to be negatively correlated with acculturative stress (Kuo \& Roysircar, 2004). Lack of English proficiency makes it hard for international students to understand class content and participate in classroom discussions. They also have to spend extra time in accomplishing readings and homework assignments. In addition to the negative impact on academic performance, the language barrier obstructs their communications with classmates, faculty, and members of the local community. When encountering problems, international students are found to be reluctant to seek help due to limited language fluency (Frey \& Roysircar, 2006).

\section{Academic Burden}

Sandhu and Asrabadi (1998) pointed out that in addition to confronting general acculturation issues, student sojourners must confront traditional academic stresses without the resources available to domestic students. Coming from different educational backgrounds, many international students find it difficult to adapt to the unfamiliar aspects of American education system, such as independent library research, frequent "pop” quizzes, making oral presentations, and active participation in informal class discussions (Mori, 2000; Pan et al., 2010). International students may also encounter culturally insensitive curricula and instructors. All this school-based stress adds an extra burden on their acculturation process. However, international students may have limited resources to deal with it (Poyrazli, Kavanaugh, Baker, \& Al-Timimi, 2004). Some resources, such as student loans and scholarships, may only be available to American students (Sandhu \& Asrabadi, 1998).

International students are usually considered the best educated students in their home countries. Their families and the whole society may 
have high expectations of academic achievement for international students. Many international students, especially those from Asian countries, are found to bear unrealistic expectations of academic performance and a greater fear of academic failure (Wei et al., 2007). Unfortunately, facing the new environment, many students find it difficult to maintain as good a performance as before. The pressure to succeed and the heightened possibility of failure impose additional stress on international students and make them vulnerable to many mental health problems.

\section{Lack of Social Support}

Lazarus and Folkman (1984) identified social support as an important coping resource for stress. Social support refers to the provision of psychological and material resources from others to help the person in stress (Crockett et al., 2007). Social support can alleviate acculturative stress and help people achieve a better mental health status (Han, Kim, Lee, Pistulka, \& Kim, 2007). People with more social support tend to experience lower levels of acculturative stress.

However, Berry and his colleagues (1987) pointed out that student sojourners do not have a full-scale social network in the host society and often lack social support when in need. Studies have found that developing social networks with American students helps international students in making successful adjustments and students who primarily socialize with American students experience less acculturative stress (Poyrazli et al., 2004). However, Frey and Roysircar (2006) found that most international students do not have American friends, either because they do not prefer to make friends with American people or because of lack of opportunities. Some international students perceive friendship in western culture to be less sincere and thus tend to socialize only with cohorts from their own countries (Mori, 2000).

\section{Barriers to Seeking Professional Help}

There are many personal concerns that prevent international students from seeking professional help, such as feelings of stigma and shame, lack of knowledge of available and existing mental health services, and cost considerations (Liu, 2009). In some developing countries, mental health and counseling services are very new. Students from such countries do not understand the concept of mental health and how mental health problems can be treated by professionals. Thus professional mental health services are not a treatment option to them.

Also, there are institutional barriers that prevent international students from seeking professional help. Many researchers have questioned the availability and accessibility of existing mental health services to ethnic 
minorities in the U.S. (Blignault, Ponzio, Rong, \& Eisenbruch, 2008; Frey \& Roysircar, 2006). Since most of the professionals in the United States are Caucasian, international students may not expect to get good services or adopt a mistrustful attitude toward American counselors due to potential cultural difference (Mori, 2000).

In conclusion, international students are very vulnerable to acculturative stress and its resulting mental health problems. The uniqueness of their problems suggests the need for research attention for international students separated from other acculturating groups. This study specifically focused on the acculturative stress of international students. The following research questions were examined: (1) What is the acculturative stress level of international students? (2) Do students vary by places of origin in the levels of acculturative stress? (3) What are the predictors of acculturative stress? Hypothetically, it was assumed that English proficiency, academic achievement, and perceived support would be negative predictors of acculturative stress.

\section{RESEARCH METHOD}

\section{Participants}

This study was conducted in a midsize U.S. Midwestern University. An online survey was sent to all the 1,355 international students with F-1 and $\mathrm{J}-1$ visa status.

Table 1: Groups by Places of Origin $(N=152)$

Place of Origin Number Percentage

\begin{tabular}{lcc}
\hline Asia & 97 & $63.82 \%$ \\
Africa & 11 & $7.24 \%$ \\
Europe & 12 & $7.89 \%$ \\
Middle East & 19 & $12.5 \%$ \\
Middle and South America & 10 & $6.58 \%$ \\
North America & 2 & $1.32 \%$ \\
\hline
\end{tabular}

A total of 186 students participated in the survey. However, 34 of the participants were excluded because they skipped a large portion of the questionnaire. Thus, the subsequent analyses were based on 152 cases. These 152 cases consisted of equal numbers of men (76) and women (76). The average age was 25 ( $\mathrm{SD}=4.62)$, ranging from 17 to 40 . Most of the participants were graduate students (64.47\%) and single (75.66\%). 
Participants were grouped by their places of origin, and people from geographically close countries were put into the same group (see Table 1). More than half of the participants in this study (63.82\%) came from Asian countries.

\section{Measures and Instruments}

Key variables in the questionnaire and their measurements are as follows. Demographic Variable. Demographic variables included age, gender, place of origin, length of stay in the United States, marital status, educational level, and major.

English Proficiency. English proficiency was measured by the Test of English as Foreign Language (TOEFL). A TOEFL score is a mandatory requirement for international students to apply to universities in the United States. However, three formats of TOEFL tests are offered in different countries, including the Paper Based TOEFL (PBT), Internet Based TOEFL (IBT), and Computer Based TOEFL (CBT). The original scales of these three tests are different. Participants taking different tests do not have comparable scores. Thus, a three-level scale of high, medium and low scores was used to make the three tests comparable. The cutoff points of high, medium and low scores were based on the information from Educational Testing Services (ETS) which provides TOEFL tests to students all over the world. A higher TOEFL score indicates better English proficiency.

Academic Achievement. Academic achievement was measured by students' grade point average (GPA), which is a common grading system in the United States. It ranges from 0 to 4 on a continuous scale. A higher GPA indicates higher academic achievement.

Perceived Support from School. Perceived support from school was measured by a 9-item scale developed by the researcher. The scale contained six questions on helpful conditions (e.g., "I feel comfortable seeking help from my professors and faculty members") and three questions on helpless conditions (e.g., "I do not know where to get help when I have a problem”). The answers were in a 5-point Likert scale ranging from 1 (strongly disagree) to 5 (strongly agree). Total scores were obtained after the answers to the helpless situations were reversely-coded. Higher total scores indicate more perceived support from school. In this study, the Cronbach's alpha of the scale was .789, which implied an acceptable level of internal consistency of the scale.

Acculturative Stress. Acculturative stress was measured by the Acculturative Stress Scale for International Students (ASSIS) developed by Sandhu and 
Asrabadi (1994). The scale contained 36 items on seven subscales, which were perceived discrimination (8 items), homesickness (4 items), perceived hate/rejection (5 items), fear (4 items), stress due to change/culture shock (3 items), guilt (2 items), and nonspecific items (10 items). The answers were in a 5-point Likert scale ranging from 1 (strongly disagree) to 5 (strongly agree). The total score of the scale varied from 36 to 180 , with a higher score indicating a higher level of acculturative stress. The authors set 109, two standard deviations above the mean score (66.32), as an alert line for counseling and psychological intervention. Previous studies have supported the reliability and validity of the ASSIS (e.g., Kaul, 2001; Constantine et al., 2004; Wei et al., 2007). In this study, the Cronbach's alpha of the ASSIS was .949, which showed high internal consistency of the scale.

\section{Research Design and Procedures}

This study was approved by the Institutional Review Board of the university. An online survey link (via SurveyMonkey) was distributed among international students through the email system of the Office of International Affairs. The online survey contained a cover letter which explained the goal of the study, the principle of voluntary participation, and the right to quit anytime without consequences. The link of online survey was sent out once a week for a total of four weeks. The study was anonymous and no personal identifying information was collected. The confidentiality of the participants was strictly protected.

\section{RESULTS}

\section{The General Acculturative Stress Level of International Students}

The average summary score of acculturative stress of the participants was 91.934, with a standard deviation of 24.372. The highest score was 159 and the lowest score was 40 . A one-sample t-test was conducted to compare the average stress level of the current sample with the validation sample provided by the authors of the scale, which was 66.32, with a standard deviation of 21.16 (Sandhu \& Asrabadi, 1994). The results showed that there was a significant difference between the two samples $(t=12.957, d f=$ $151, p<.001)$. Participants in this study demonstrated a significantly higher level of acculturative stress than the validation sample of international students. According to Sandhu and Asrabadi (1998), scores higher than 109 should be interpreted as a warning sign indicating the need for counseling and psychological interventions. In this study, $22.4 \%$ of the participants scored higher than 109, which indicated serious stress levels in this university.

A One-way ANOVA was conducted to compare the stress levels by nationalities. The results showed that there was significant difference in 
acculturative stress by nationalities $(F(5,145)=2.488, p=0.034)$. A Tukey HSD was conducted as the follow-up test and a significant difference was found between European students and Middle Eastern students $(p=0.025)$. The mean score of Middle Eastern students was 104.75, while the mean score of European students was 77.16. Middle Eastern students had significantly higher levels of acculturative stress than European students. No significant difference was found among other nationalities.

\section{Correlations among English Proficiency, Academic Achievement, Perceived Support from School, and Acculturative Stress}

Correlations, means and standard deviations of all variables are presented in Table 2. The results showed that academic achievement $(r=.212)$ and perceived support $(r=.623)$ from school were significantly correlated with acculturative stress. Students with better academic achievement and more support from school had lower levels of stress. However, English proficiency was not significantly correlated with stress $(r=-.134)$.

Table 2: Correlations among English Proficiency, Academic Achievement, Perceived Support from School, and Acculturative Stress

\begin{tabular}{lllll}
\hline Measure & 1 & 2 & 3 & 4 \\
\hline 1. English proficiency & 1.00 & & & \\
2. Academic achievement & 0.11 & 1.00 & & \\
3. Perceived support from school & 0.13 & $0.206^{*}$ & 1.00 & \\
4. Acculturative stress & -0.134 & $0.212^{* *}$ & $0.623^{* *}$ & 1.00 \\
Mean & 2.35 & 3.43 & 32.24 & 91.934 \\
$S D$ & 0.707 & 0.724 & 5.692 & 24.372 \\
\hline
\end{tabular}

${ }^{*} p<.05,{ }^{* *} p<.01$

Perceived Support from School as a Predictor of Acculturative Stress To identify the predictors of acculturative stress and differentiate the contribution of each independent variable, a hierarchical regression was conducted. The order of entry was based on the judgment of the researcher. First, age and years of staying in the United States were entered because demographic variables are basic predictors that should be controlled for in order to minimize their influence on other predictors. In the second step, English proficiency and academic achievement were entered. Both of them were school-related variables, and they were equally important to the researcher. Perceived support from school was entered in the last step because this was the variable that was most highly correlated with acculturative stress and of most interest to the researcher. Also, separating 
perceived support and academic achievement would reduce the problem of multicollinearity since they were significantly correlated to each other.

The unique variance accounted for by each step and the regression coefficient of each variable are presented in Table 3. Age and years in the U.S. did not account for a significant amount of variance in acculturative stress $\left(R^{2}=2.9 \%\right)$. In contrast, English proficiency and academic achievement added a significant amount of variance $\left(R^{2}=6.2 \%\right)$. However, none of the variables had significant regression coefficients, which meant they did not make significant contribution in predicting acculturative stress. Perceived support from school added a significant amount of variance $\left(R^{2}=\right.$ 42.1\%), and it was the only significant predictor of acculturative stress (Beta $=-0.683, t=-10.083, p<.001)$. When the scores of perceived support increased 1 standard deviation, there would be 0.683 standard deviation decrease in the scores of acculturative stress.

Table 3: Hierarchical Regression Predicting Acculturative Stress with Accounted Variance and Regression Coefficient

\begin{tabular}{|c|c|c|c|c|c|c|}
\hline & $R^{2}$ & $\Delta R^{2}$ & $p$ & Variables & Beta & $p$ \\
\hline \multicolumn{7}{|c|}{ Step } \\
\hline \multirow[t]{2}{*}{1} & 0.029 & 0.029 & 0.167 & Age & 0.580 & 0.554 \\
\hline & & & & Years in US & -0.186 & 0.060 \\
\hline \multicolumn{7}{|c|}{ Step } \\
\hline \multirow[t]{6}{*}{2} & 0.091 & 0.062 & 0.020 & Age & 0.101 & 0.298 \\
\hline & & & & Years in US & -0.174 & 0.072 \\
\hline & & & & English & & \\
\hline & & & & proficiency & -0.098 & 0.270 \\
\hline & & & & Academic & & \\
\hline & \multicolumn{6}{|c|}{ Step } \\
\hline \multirow[t]{7}{*}{3} & 0.512 & 0.421 & 0.000 & Age & 0.111 & 0.123 \\
\hline & & & & Years in US & -0.039 & 0.589 \\
\hline & & & & English & & \\
\hline & & & & proficiency & -0.032 & 0.622 \\
\hline & & & & Academic & (01 & 0124 \\
\hline & & & & Perceived support & -0.101 & 0.104 \\
\hline & & & & from school & -0.683 & 0.000 \\
\hline
\end{tabular}




\section{DISCUSSION}

The results indicated that the international students in this university demonstrated high levels of acculturative stress. Among all the groups, students from the Middle East had the highest stress levels (104.75), followed by students from Central and South America (95.67) and Africa (95.12). This is not consistent with previous studies, many of which found that students from Asian countries experienced more acculturative stress due to large cultural disparities and language barriers (Poyrazli et al., 2004). A possible reason for the inconsistency might be that most of the international students in this university came from Asian countries. They provide social support to each other, which helps to alleviate acculturative stress. Another possible reason is that there is rarely any study on the acculturative stress of students from the Middle East and Africa. Their acculturative stress might not be exposed to research attention.

Among all the variables, perceived support from school was the only significant predictor of acculturative stress, after the other predictors had been controlled. The results indicated that support from school is very important to international students in their acculturation process. Support from school does not only refer to tangible support such as a culturally friendly environment and facilities, but also moral support from people whom international students interact with, such as classmates, faculty, and staff members. A university is like a small society. For many international students, school is the primary place they encounter American culture. With sufficient support from school, students can have positive acculturative experiences and lower stress levels. Otherwise, students may feel helpless when they have problems and be overwhelmed by the acculturative stress.

Age, years of stay in the U.S., English proficiency and academic achievement were not significant predictors in this study, which is not consistent with previous studies (Constantine et al., 2004; Kuo \& Roysircar, 2004; Wei et al., 2007). One possible reason is that the sample of this study is quite homogeneous. As college students, the participants did not vary much in age (Mean $=25.77, S D=4.628)$ and years of stay in the U.S. $($ Mean $=2.23, S D=2.492)$. Without enough variation, the statistical tests cannot capture whether the change in one variable is accounted for by another variable. The same problem occurred with English proficiency and academic achievement. However, the limited variation in these two variables was mainly due to inappropriate measurement instead of the homogeneity of the sample, which will be addressed in the next section. 


\section{LIMITATIONS AND RECOMMENDATIONS}

The primary limitation of this study is that the response rate was low and the drop off rate was high. The questionnaire was sent to a total of 1,355 students, but only 186 of them participated in the survey. The response rate was $13.7 \%$, which was not sufficient for capturing the experiences of international students in this university. Among those participants, only 152 finished the entire questionnaire, while the other 34 people only answered part of the questionnaire. It was obvious that English proficiency was a serious barrier that prevented some students from completing the questionnaire. Students with better language ability would be more likely to finish the survey, while those without enough language proficiency would feel incapable or not confident enough to finish the long English questionnaire. In future studies, it would be advisable to develop culturally sensitive and language appropriate scales, instead of one scale for all, to measure the acculturative stress of international students from different countries. If the scale is in the native languages of international students, they will have more motivation and language capacity to finish the survey.

The second limitation is that the measurement of English proficiency was ordinal rather than continuous. Because there are three formats of TOEFL tests operated in different countries, the researcher had to develop an ordinal scale to make the scores of the three formats comparable with each other. However, it resulted in a great loss of information by converting a continuous variable into an ordinal variable. In future studies, it would be better to use the real TOEFL scores and convert all of them into the scale of one format of test. For example, researchers could convert the scores of CBT and PBT into the scale of IBT, which has been promoted by ETS recently to take the place of the other two formats.

Finally, the results of this study cannot be generalized to the general population of international students. The sample was not randomly drawn and thus the representativeness of the sample is doubtful. Also, the study was conducted only in one university in Midwestern America. It is possible that the situation would be different in Eastern and Western coastal areas for international students.

\section{IMPLICATIONS}

For researchers, it is necessary to develop culturally competent assessment tools for acculturative stress among international students. As shown in this study, the language barrier severely impacted the response rate. In the future, scales should be developed in the original languages of international students. Researchers should also try to identify the institutional, political, 
and historical reasons that contribute to the high levels of acculturative stress among international students and remove the institutional barriers that prevent international students from approaching mental health services.

For practitioners in helping professions, it is important to implement culturally competent practice. Since international students are usually hesitant to seek help on their own, it is crucial for service providers to take a proactive approach (Sandhu \& Asrabadi, 1994, 1998). For students who are not familiar with mental health and counseling services, practitioners could first educate them about community resources and try to increase the visibility and the accessibility of their services (Mori, 2000). Practitioners should also educate the host community about the cultures of international students and facilitate intercultural communication. Establishing local social support systems will help international students to alleviate acculturative stress (Liu, 2009).

Since perceived support from school is a significant predictor of acculturative stress, universities should take responsibility in providing more services to international students. It is important for host universities to increase the diversity of staff members in organizations, such as offices for international students, counseling center, and health services. Sufficient representation of cultural diversity among staff members will enhance the international students' confidence in accessing mental health services (Mori, 2000).

\section{REFERENCES}

Berry, J.W. (2003). Conceptual approaches to acculturation. In K.M. Chun, P.B. Organista, \& G. Marin (Eds.), Acculturation: Advances in theory, measurement, and applied research. Washington D.C.: American Psychological Association.

Berry, J.W., \& Kim, U. (1987). Acculturation and mental health. In P. Dasen, J.W. Berry \& N. Sartorius (Eds.), Cross-cultural psychology and health: Towards application. London: Sage.

Berry, J.W., Kim, U., Minde, T., \& Mok, D. (1987). Comparative studies of acculturative stress. International Migration Review, 21, 491-511.

Blignault, I., Ponzio, V., Rong Y., \& Eisenbruch, M. (2008). A qualitative study of barriers to mental health service utilization among migrants from mainland China in southeast Sydney. International Journal of Social Psychiatry, 54(2), 180-190.

Constantine, M.G., Okazaki, S., \& Utsey, S.O. (2004). Self-concealment, social self-efficacy, acculturative stress, and depression in African, 
Asian, and Latin American international college students. American Journal of Orthopsychiatry, 74, 230-241.

Crockett, L.J., Iturbide, M.I., Torres Stone, R.A., McGinley, M., Raffaelli, M., \& Carlo, G. (2007). Acculturative stress, social support, and coping: Relations to psychological adjustment among Mexican American college students. Cultural Diversity and Ethnic Minority Psychology, 13(4), 347-355.

Frey, L.L., \& Roysircar, G. (2006). South Asian and East Asian international students' perceived prejudice, acculturation and frequency of help resource utilization. Journal of Multicultural Counseling and Development, 34, 208-222.

Gribble, C. (2008). Policy options for managing international student migration: the sending country's perspective. Journal of Higher Education Policy and Management, 30(1), 25-39.

Han, H.R., Kim, M., Lee, H.B., Pistulka, G.P., \& Kim, K.B. (2007). Correlates of depression in the Korean American elderly: Focusing on personal resources of social support. Journal of Cross Cultural Gerontology, 22, 115-127.

Hwang, W.C., \& Ting, J.Y. (2008). Disaggregating the effects of acculturation and acculturative stress on the mental health of Asian students. Cultural Diversity and Ethnic Minority Psychology, 14(2), 147-154.

Institute of International Education. (2014). Open Doors 2013: International students in the United States and study abroad by American students are at all-time high. Retrieved August 2014, from http://www.iie.org/Who-We-Are/News-and-Events/PressCenter/Press-Releases/2013/2013-11-11-Open-Doors-Data

Kaul, A. (2001). Predictors of positive adaptation among international students in the United States. Unpublished doctoral dissertation, University of Memphis.

Kuo, C.H., \& Roysircar, G. (2004). Predictors of acculturation for Chinese adolescents in Canada: Age of arrival, length of stay, social class and English reading ability. Journal of Multicultural Counseling and Development, 32, 143-154.

Lazarus, R.S., \& Folkman, S. (1984). Stress, appraisal, and coping. New York: Springer.

Leong, F.T.L., \& Chou, E.L. (2002). Counseling international students. In P.B. Pedersen, J.G. Draguns, W.J. Lonner, \& J.E. Trimble (Eds.), Counseling across cultures (5 ${ }^{\text {th }}$ ed.) (pp. 185-207). Thousand Oaks, CA: Sage. 
Liu, M. (2009). Addressing the mental health problems of Chinese international college students in the United States. Advances in Social Work, 10(1), 69-86.

Mori, S.C. (2000). Addressing the mental health concerns of international students. Journal of Counseling and Development, 78, 137-144.

National Academies. (2005). Policy implications of international graduate students and postdoctoral scholars in the United States. Washington, DC: National Academies Press.

Pan, J.Y., Yue, X., \& Chan, C.L.W. (2010). Development and validation of the acculturative hassles scale for Chinese Students (AHSCS): An example of mainland Chinese university student in Hong Kong. Psychologia, 53 (3), 163-178.

Poyrazli, S., Kavanaugh, P.R., Baker, A., \& Al-Timimi, N. (2004). Social support and demographic correlates of acculturative stress in international students. Journal of College Counseling, 7, 73-82.

Redfield, R., Linton, R., \& Herskovits, M.J. (1936). Memorandum on the study of acculturation. American Anthropologist, 38, 149-152.

Sandhu, D.S., \& Asrabadi, B.R. (1994). Development of an acculturative stress scale for international students: Preliminary findings. Psychological Reports, 75, 435-448.

Sandhu, D.S., \& Asrabadi, B.R. (1998). An acculturative stress scale for international students: A practical approach to stress measurement. In C.P. Zalaquett \& R.J. Wood (Eds), Evaluating stress: $A$ book of resources, V.2. (pp. 1-33). Lanham, MD: Scarecrow Press.

Wei, M., Heppner, P.P., Mallen, M.J., Ku, T., Liao, Y., \& Wu, T. (2007). Acculturative stress, perfectionism, years in the United States, and depression among Chinese international students. Journal of Counseling Psychology, 54(4), 385-394.

Note: I would like to thank Ms. Sandra Lemons, the Assistant Director for Student Services at IUPUI Office of International Affairs, for supporting and assisting my study.

JIERU BAI is an assistant professor of social work. Her research interests include acculturation and acculturative stress; mental health of immigrants and their families; culturally competent assessment and practice; program evaluation; and advanced statistical methods/mixed methods. She mainly teaches human behavior and social environment, research methods, and diversity class. Email: jbai@unomaha.edu 